\section{Outcomes of public concern in schizophrenia}

\author{
IAIN KOOYMAN, KIMBERLIE DEAN, SAMUEL HARVEY \\ and ELIZABETH WALSH
}

\begin{abstract}
Background Schizophrenia is known to be associated with a range of adverse outcomes, which have an impact at the societal level and are therefore of public concern.
\end{abstract}

\begin{abstract}
Aims To examine the epidemiology and methods for measuring six adverse outcomes in schizophrenia: violence, victimisation, suicide/self-harm, substance use, homelessness and unemployment.
\end{abstract}

Method A review of the literature was carried out for each adverse outcome, with attention to critical appraisal of existing measurement tools.

Results Schizophrenia is associated strongly with all six outcomes, although research has mainly focused on violence. Each outcome acts as a risk factor for at least some of the other outcomes. There are few standardised or validated measures for these 'hard' outcomes. Each measure has inherent biases but a growing trend is for these to be minimised by using multiple measures.

\section{Conclusions A single instrument which systematically measures multiple societal outcomes of schizophrenia would be extremely useful for both clinical and research purposes.}

Declaration of interest None.
The asylum movement of the 19th century could be regarded as part of a state-guided sanitary movement to cleanse society of the harmful impact of those with mental illness. Although stigmatisation and fear were instrumental in this process, there is now strong evidence for genuine adverse outcomes of schizophrenia on society. Deinstitutionalisation and community care, which have become widespread since the 1970s, have re-exposed the general public to such outcomes, accompanied by a fear of violence, and particularly homicide perpetrated by people with schizophrenia, fuelled by media attention. Suicide and self-harm are much more prevalent outcomes in this group, however, and victimisation of people with schizophrenia is especially neglected. Substance misuse, unemployment and homelessness are also prevalent outcomes of public concern. The prevalence and risk factors for each of these six adverse outcomes in schizophrenia will be reviewed, with an examination of the contribution to society as a whole. There are few validated instruments for measuring these 'societal outcomes', but their assessment at both the individual and population level will be considered.

\section{VIOLENCE}

\section{Prevalence and risk factors}

It is now widely accepted that people with schizophrenia are more likely to behave violently. Varying estimates of the prevalence and relative risk of violence in schizophrenia are dependent on the definition of schizophrenia, the type of violence measured and the location of the study. There is also no consensus as to which variables should be treated as confounding factors or mediators. Unselected birth cohorts have reported relative risks of between 2 and 7 times for serious violence compared with the general population (Tiihonen et al, 1997; Arseneault et al, 2000; Brennan et al, 2000). People with schizophrenia have been shown to be convicted of a greater number of violent crimes than their neighbours of a similar age (Wallace et al, 2004) and schizophrenia is overrepresented in prisoners (Teplin, 1990; Eronen et al, 1996). Although schizophrenia independently increases the risk of committing violence (Brennan et al, 2000), this risk is increased significantly by comorbid substance misuse (Wallace et al 2004), personality disorder (Moran \& Hodgins, 2004), a lack of adherence to medication (Swanson et al, 1997) and acute psychotic symptoms (Taylor, 1998).

\section{Risk to society}

With most research to date focusing on relative risk, it is encouraging to see estimates of absolute risk emerging in the literature. The population attributable risk (i.e. the fall in levels of violence in society that would occur if violent incidents by people with schizophrenia were discarded) is an approximate calculation. This approach assumes causality between schizophrenia and violent conviction and fails to take account of associated factors, such as substance misuse and personality disorders. Wallace et al (2004) estimated that 6$11 \%$ of violent convictions are attributable to schizophrenia. Fazel \& Grann (2006) found a population attributable risk fraction of just $2.3 \%$, which increased to $5 \%$ for psychosis. They suggest that in countries with more liberal gun laws, the attributable risk is lower for homicide, but others argue that those with schizophrenia are responsible for $5-10 \%$ of homicides irrespective of the baseline homicide rate (Wallace et al, 2004).

\section{Measurement}

Measurement of violent behaviour has relied upon various single or combined sources of information (self-report, informant, case notes, official records). All single sources bias towards underreporting: self-report from a desire for social acceptability or fear of adverse consequences of reporting; informants, often nominated by patients, being unreliable or unaware; and case notes being invariably incomplete. The proportion of violent acts leading to arrest, prosecution and conviction varies with the intensity and quality of policing, the behaviour of the suspect, the availability of diversion to the mental health system and the severity of offence. Most people who are violent are not convicted (Elliott et al, 1986). Only the more serious violent 
acts lead to conviction; hence the association between schizophrenia and more minor forms of violence is impossible to estimate from official sources.

The recent use of multiple combined measures has improved the detection of violent behaviour. Steadman et al (1998) showed that the detection of violence increased steadily as methods were combined, and reached six times the rate of official convictions alone. Multiple measures require judgements about what constitutes a single violent event and handling inconsistencies between reports.

The definition of violence varies enormously between studies, and most neglect contextual aspects. The MacArthur Community Violence Interview (Steadman et al, 1998) in the USA is an important step towards consistency. It measures lifetime violence, and includes information on recent aggressive behaviour and victimisation. It incorporates a clear and structured definition of different levels of violence and considers the context for each episode. There is also a version for use with collateral sources. Encouragingly, its use is increasing (Elbogen et al, 2006; Swanson et al, 2006).

\section{Predicting violence}

Measuring violence is less problematic than predicting it. Assessing the risk of violence has become an increasingly important part of clinical practice in psychiatry, with time and resource implications. The clinical usefulness of specific risk assessment procedures depends on: (a) the accuracy of prediction (predictive validity); (b) the applicability to the patient group; and (c) the ability of clinicians to act on the results to reduce predicted risk.

Predictive validity has been at the heart of the debate concerning two differing approaches - actuarial $v$. clinical risk assessment. The former relies on the identification of largely static risk factors defining at-risk groups within populations while the latter is an individually focused case formulation, which underpins routine clinical practice. To combine the advantages and minimise the disadvantages of the two approaches, several structured risk assessment instruments have been devised and tested (Dolan \& Doyle, 2000), including the Violence Risk Scale (VRS; Wong \& Gordon, 2000)

A statistical assessment of predictive validity is essential both for considering the clinical value of a particular instrument and for comparing instruments. Receiver operating characteristics (ROC) analysis integrates the concepts of sensitivity and specificity, and are relatively independent of the base rate of violence within the population (Kroner, 2005). A recent UK study compared the relative efficacy of the Historical Clinical Risk 20 items scale (HCR20; Douglas et al, 2001), the Psychopathy Checklist Screening Version (PCL:SV; Hart, et al, 1995) and the Offender Group Reconviction Scale (OGRS; Copas \& Marshall, 1998) prospectively over 2 years in a group discharged from a medium secure unit (Gray et al, 2004). All three instruments were predictive of offending over the follow-up period, but the purely criminogenic scale (OGRS) performed best. This finding that actuarial instruments outperform even structured clinical assessments in mentally disordered offenders is consistent across different settings (Bonta et al, 1998), but both types of assessment outperform unaided clinical judgement. However, instruments validated in offenders may have less predictive validity in general adult than forensic psychiatry. The HCR-20 has been validated in both settings (Douglas et al, 2001).

In clinical practice the usefulness of any risk assessment method will also depend on the implications for intervention. Static factors such as gender and past criminal behaviour offer limited scope to inform clinical intervention. Consideration of dynamic, clinical factors, such as active psychotic symptoms and substance misuse, may contribute more to the usefulness of a risk assessment instrument in clinical practice (Mills, 2005), enabling the shift from risk assessment to risk management or risk reduction.

Imperfect risk prediction has serious implications for individuals. Even instruments with relatively high predictive validity will generate both false-positives and false-negatives. The potential implications have been elegantly demonstrated by Buchanan \& Leese (2001) who pooled results from 23 studies employing violence risk assessments and concluded that 6 people would need to be detained to prevent one violent act. Routine violence risk assessment might also detract from the consideration of other outcomes, such as those reviewed below.

\section{VICTIMISATION}

\section{Prevalence and risk factors}

People with severe mental illnesses such as schizophrenia are more likely to be victims of violence than perpetrators of a violent act (Brekke et al, 2001). Silver (2002) reported that people with severe mental illness and/or personality disorder were more than twice as likely to be the victims of violence than their neighbours. Recent US figures are much higher (Teplin $e t$ al, 2005) and are supported by findings from the Dunedin Study, in which over half of those with schizophreniform disorder reported being assaulted in a 12-month period (Silver et al, 2005).

It has been suggested that this increased risk of victimisation arises from increased aggressive behaviour. Although this may play a part, the increased risk of victimisation in people with psychosis remains irrespective of the individual's own violent behaviour (Hiday et al, 2002; Silver, 2002). People with schizophrenia now live within the community and Silver (2002) has shown that their victimisation can be mediated by conflict within social relationships. Elevated rates have also been found to be prospectively associated with comorbid personality disorder, young age at illness onset, previous victimisation and infrequent contact with family members (further details available from K.D.).

\section{Risk to society}

Little is known about the impact of victimisation on either the individual or society. It is likely that victims of violence who have schizophrenia will be particularly vulnerable to a range of adverse outcomes, such as homelessness (Lam \& Rosenheck, 1998), which have significant cost implications.

\section{Measurement}

Victimisation is poorly recognised in clinical practice (Cascardi et al, 1996), often neglected in schizophrenia research and optimal methods of measurement have yet to be established. Two types of instruments have been used. Questionnaires have been designed for use with people with mental disorders, but not specifically to examine victimisation. The MacArthur Community Violence Interview includes a number of questions on victimisation and its context (Silver, 2002). The Lancashire Quality of Life Profile includes items on experience of victimisation, but without detail of the frequency, severity or context (Oliver, 1991). Questionnaires have also been designed to examine victimisation in the general population. The National Crime Victimisation Survey was applied to a sample of people with serious mental illnesses by Teplin et al, 2005 who 
described the instrument as the most comprehensive available to assess victimisation because it elicits detailed information about each event reported. The instrument required some modification for use with people with mental disorders.

As many acts of violence are not reported to the police (and this may be more likely for victims with mental illnesses) selfreport measures will continue to be the best method for obtaining data on victimisation. Reporting past victimisation may be subject to recall difficulties and may not be reliable. Incorporation of 'bounding interviews' to establish reference points for future recalling of index events might reduce 'telescoping', whereby incidents occurring prior to the required recall period are reported (Teplin $e t$ al, 2005). Collateral sources (family members, keyworkers or residential support staff), although generally likely to underestimate victimisation, may complement participant-reporting and enable some assessment of reliability. As with the measurement of all societal outcomes, the use of multiple sources of information is optimal.

Attention has been focused on establishing the prevalence of victimisation and associated risk factors, rather than understanding in detail its nature, context and impact on those with schizophrenia and other serious mental disorders. Future measures of victimisation should consider factors such as acute symptoms, service contacts and presence of comorbid illness. In addition to exploiting multiple sources, instruments should be specifically designed for people with mental illness and should assess victimisation in detail.

\section{SUICIDE AND SELF HARM}

\section{Prevalence and risk factors}

Suicide is a significant cause of premature death in people with schizophrenia (Caldwell \& Gottesman, 1992), with lifetime estimates ranging from 5 to $13 \%$ (Miles, 1977; Caldwell \& Gottesman, 1990; Palmer et al, 2005). Most suicides occur soon after illness onset (Palmer et al, 2005 ) and may have increased greatly over the past century (Healy et al, 2006). Nonfatal acts of self-harm are also increased, with a study of people with chronic schizophrenia finding that $38 \%$ had at least one episode of self-harm in a 2- to 12-year follow-up period (Breier et al, 1991).

A recent meta-analysis identified the following as risk factors for suicide in schizophrenia: recent loss; fear of mental disintegration; agitation or motor restlessness; poor adherence to treatment; drug misuse; and previous depressive disorders and suicide attempts (Hawton et al, 2005). Suicidal behaviour in individuals with schizophrenia does not appear to be associated with particular psychotic symptoms. The usual higher incidence of selfharm in females is not present in schizophrenia (Haw et al, 2005) and, strikingly, people witih schizophrenia from more affluent socio-economic groups are at increased risk of self-harm (further details available from the authors). Approximately $20 \%$ of suicides in those under 35 are accounted for by schizophrenia (Appleby et al, 1999a).

\section{Measurement}

Accurate estimation of suicide rates is difficult; official statistics and coroners' reports are known to underestimate suicide rates, but such errors do not invalidate epidemiological conclusions based on these figures (Sainsbury \& Jenkins, 1982; Speechley \& Stavraky, 1991). Some estimates rely on proportionate mortality (the percentage of those dead who died by suicide) rather than case fatality rates (the percentage of a sample of patients who will die by suicide). The use of proportionate mortality rates assumes a constant rate of suicide, which given the increased rate of early suicide in schizophrenia might lead to an overestimate of the lifetime suicide risk (Palmer et al, 2005).

A number of risk factors have been consistently associated with suicide in schizophrenia, but their low sensitivity and specificity, plus the rarity of suicide, diminish their clinical usefulness. Evaluating the predictive power of suicide risk factors in psychiatric in-patients, Powell et al (2000) found several to be strongly associated, but the resulting model was unable to predict the majority of suicides without an unacceptably high false-positive rate.

The definition of self-harm is not well established (Skegg, 2005). Behaviours vary and there is no consensus on inclusion of suicidal intent, which can be difficult to measure in psychosis. Clinical records underestimate self-harm compared with self-report questionnaires (Hawton et al, 2002), but self-report alone may be unreliable. Some studies combine self-report with review of routine case records. Instruments including a limited number of items relating to self-harm have been used to estimate its prevalence in schizophrenia. These include the WHO Life Chart (World Health
Organization, 1992), the Structured Clinical Interview for DSM (SCID; Spitzer et al, 1994), the Functional Assessment Rating Scale (FARS; Ward \& Dow, 1995) and the Psychiatric and Personal History Schedule (PPHS; Jablensky et al, 1992).

The European Parasuicide Study Interview Schedule (EPSIS) has been specifically developed to examine parasuicidal behaviour, suicidal thoughts and associated factors in detail (Platt et al, 1992), but has only been used to a limited extent in samples with psychotic disorders (Nordentoft et al, 2002).

\section{SUBSTANCE USE}

\section{Prevalence and risk factors}

In the USA $40-60 \%$ of people with schizophrenia misuse substances, excluding cigarettes (Cantor-Graae et al, 2001). The pattern of substances misused varies locally but rates are universally higher than in the healthy population (McCreadie et al, 2002). Substances misused include all substance classes and appear to be increasing dramatically (Boutros et al, 1998), although proportionally to the rise within the general population (Wallace et al, 2004).

Substance misuse is increased prior to the onset of schizophrenia. This might be due to causality of psychosis by drugs such as cannabis (Arsenault et al, 2004; Fergusson et al, 2003) or confounders such as a shared underlying neurological vulnerability (Janowsky et al, 1973; Liberman et al, 1986) or antisocial personality disorder (Reiger et al, 1990). Substance misuse is also an outcome of schizophrenia. A substantial number of people use drugs for the first time after the onset of schizophrenia (Hambrecht \& Hafner, 1996). Such patients with dual diagnosis report using street drugs to counter depression and anxiety (Dixon et al, 1990; Addington \& Duchak, 1997), negative symptoms such as apathy and anhedonia (Pristach \& Smith, 1996), and to assist sleeping and reduce extrapyramidal side-effects. Cocaine use may temporarily reduce negative symptoms (Serper et al, 1996). Evidence that people use street drugs to treat positive symptoms is equivocal. People with schizophrenia often feel alienated from society (Sainsbury Centre for Mental Health, 1998) and, rejected by peers, may drift into networks of drug users, who may be more accepting of them (Lamb, 1982).

Substance misuse is clearly an adverse outcome: people with dual diagnosis are 
Table I Standardised tools for measuring substance use in people with mental disorders

\begin{tabular}{|c|c|c|c|c|}
\hline Measurement tool & $\begin{array}{l}\text { Information } \\
\text { source }\end{array}$ & Scale & Advantages & Disadvantages \\
\hline $\begin{array}{l}\text { Alcohol Use Disorders Identification } \\
\text { Test (AUDIT; Saunders et al, I993) } \\
\text { and Drug Use Disorders Identification } \\
\text { Test (DUDIT; Berman et al, 2005) }\end{array}$ & $\begin{array}{l}\text { Self-report } \\
\text { questionnaires }\end{array}$ & $\begin{array}{l}\text { I0 or II items Information } \\
\text { on frequency and quantity, } \\
\text { features of associated harm } \\
\text { and dependency }\end{array}$ & $\begin{array}{l}\text { High sensitivity and } \\
\text { specificity in prison and } \\
\text { general populations } \\
\text { Commonly used }\end{array}$ & $\begin{array}{l}\text { Not validated for healthy } \\
\text { populations }\end{array}$ \\
\hline $\begin{array}{l}\text { Alcohol Use Scale (AUS) and Drug } \\
\text { Use Scale (DUS; Drake et al, 1990) }\end{array}$ & Clinician-rated & $\begin{array}{l}\text { 5-point Likert scale } \\
\text { (I= abstinence; } \\
\text { 2= use, no impairment; } \\
3 \text { = misuse; } 4=\text { dependency; } \\
5=\text { severe dependency) }\end{array}$ & $\begin{array}{l}\text { Validated in populations } \\
\text { with mental illness } \\
\text { Good screening tool }\end{array}$ & $\begin{array}{l}\text { Subjective judgement, relies } \\
\text { on clinician knowlege and } \\
\text { expertise } \\
\text { Does not enhance knowledge } \\
\text { about substance use }\end{array}$ \\
\hline $\begin{array}{l}\text { Substance Use Rating Scale } \\
\text { (Duke et al, 1994) }\end{array}$ & $\begin{array}{l}\text { Self-report or } \\
\text { clinician-rated } \\
\text { versions }\end{array}$ & $\begin{array}{l}\text { Maximum lifetime use } \\
\text { plus amount used in the } \\
\text { preceding month }\end{array}$ & $\begin{array}{l}\text { Addresses use of legal } \\
\text { substances as well as illegal }\end{array}$ & Only measures use \\
\hline $\begin{array}{l}\text { Severity of Dependence Scale } \\
\text { (Gossop et al, 1995) }\end{array}$ & $\begin{array}{l}\text { Self-report, } \\
\text { brief questionnaire }\end{array}$ & $\begin{array}{l}5 \text { items measuring psychologi- } \\
\text { cal features of dependency }\end{array}$ & $\begin{array}{l}\text { Good for measuring } \\
\text { stimulant dependency }\end{array}$ & $\begin{array}{l}\text { No measure of physical } \\
\text { features of dependency } \\
\text { Validated in heroin and } \\
\text { stimulant users without } \\
\text { mental illness }\end{array}$ \\
\hline $\begin{array}{l}\text { Maudsley Addictions Profile } \\
\text { (MAP; Marsden et al, 1998) }\end{array}$ & Clinician-rated & $\begin{array}{l}60 \text { items across substance } \\
\text { use, health risk, physical/ } \\
\text { psychological health and } \\
\text { personal/social functioning } \\
\text { domains }\end{array}$ & $\begin{array}{l}\text { Thorough assessment of harm } \\
\text { Includes measures of employ- } \\
\text { ment and criminal behaviour }\end{array}$ & $\begin{array}{l}\text { Not validated in populations } \\
\text { with mental illness }\end{array}$ \\
\hline
\end{tabular}

generally younger, less adherent to treatment (Swofford et al, 1996), have more positive symptoms (Hambrecht \& Hafner, 1996), more psychiatric admissions (Hunt et al, 2002), higher rates of violence (Hodgins, 1992; Scott et al, 1998), are more likely to die by suicide (Appleby et al, 1999b), be unemployed (Seibyl et al, 1993), homeless (Drake et al, 1991; Soyka et al, 1993) and create excess service costs (Hoff \& Rosenheck, 1999). The extent of the damage is underlined by this group's superior premorbid intellectual functioning and socio-economic status compared with people with schizophrenia who do not misuse substances (Kirkpatrick et al, 1996; Sevy et al, 2001). Much of the three-fold higher mortality in schizophrenia can be attributed to excess substance misuse, especially cigarette smoking (Brown et al, 2000).

\section{Measurement}

Clinicians and family informants are poor at estimating substance misuse in the absence of dependency, and patients grossly underreport their use (particularly for stimulants and opiates) when compared with toxicology screens (Swartz et al, 2003). Detection by professionals depends on the level of training in drug/alcohol issues and familiarity with the patient
(Ananth et al, 1989). Staff suspicion and questioning should be combined with toxicology screens, but these also require staff training and provide only binary outcomes (i.e. used/not used). Saliva tests avoid the risk of patients corrupting samples and awkward supervision, but it remains unclear whether they are more or less accurate than urine tests. Breathaliser tests are practical and valid for measuring alcohol intoxication. For detecting more distal substance use, radioimmunoassay of hair specimens is nonintrusive and reliable (Swartz et al, 2003).

'Use' can be quantified by frequency, quantity or duration, and should be differentiated from 'misuse' and 'dependency', but for convenience, poorly defined pooled categories have been preferred. Common examples include 'substance use disorder' (Mueser \& Drake, 1998) and 'problem use' which has been variably equated to harmful or dependent use combined (McCreadie, 2002), or any use (for example Duke et al, 2001). Studies vary in the extent of substance inclusion, particularly of legal (nicotine, caffeine, alcohol) and prescribed substances (benzodiazepines, anticholinergics). Substance use diagnoses can refer to current, past or lifetime criteria.

Most research studies use case notes or unstructured interviews. Structured interviews minimise information variance and are more reliable (Blanchard \& Brown, 1998). Some standardised measurement tools are listed in Table 1 but these are rarely used outside of research. Multiple measures are increasingly being used (Swartz et al, 2006).

Routine screening for substance misuse in people with schizophrenia is an important component of assessing risk and planning treatment. Self-report measures assessing readiness to change are reliable (Carey et al, 2001). However, evidence for effectiveness of psychological interventions targeting substance misuse over standard care for people with schizophrenia has been lacking (Ley et al, 2000), but is improving (Haddock et al, 2003).

\section{HOMELESSNESS}

\section{Prevalence and risk factors}

Homelessness is a well recognised outcome of schizophrenia but there have been few attempts to quantify it. Rates vary across borders and time. A US community study (Folsom et al, 2005) found that about a fifth of more than 4000 people with schizophrenia had no fixed address, which was 2.4 times higher than for major depression. The European Schizophrenia Cohort 
Table 2 Studies of the effectiveness of individual placement schemes for people with severe mental illness

\begin{tabular}{|c|c|c|c|}
\hline \multirow[t]{2}{*}{ Reference } & \multicolumn{2}{|c|}{$\begin{array}{l}\text { Outcome difference for } \\
\text { those in employment, \% }\end{array}$} & \multirow[t]{2}{*}{ Other employment outcomes measured } \\
\hline & IPS & Controls & \\
\hline \multirow[t]{5}{*}{ Drake et al (1996) } & 78.1 & 40.3 & Hours worked per week \\
\hline & & & Wages earned \\
\hline & & & Number working more than 20 hours per week \\
\hline & & & Non-vocational outcomes (self-esteem, quality \\
\hline & & & of life, symptoms, hospitalisation) \\
\hline \multirow[t]{5}{*}{ Drake et al (1999) } & 60.8 & 9.2 & Total earnings \\
\hline & & & Job satisfaction \\
\hline & & & Non-vocational outcomes \\
\hline & & & Worked for 20 hours per week at some point \\
\hline & & & Sheltered employment \\
\hline \multirow[t]{3}{*}{ Lehman et al (2002) } & 27 & 7 & Doing any work at all \\
\hline & & & Number of hours \\
\hline & & & Wages earned \\
\hline \multirow[t]{2}{*}{ Mueser et al (2004) } & 73.9 & $18.2 / 27.5^{\prime}$ & Paid work \\
\hline & & & Non-vocational outcomes \\
\hline \multirow[t]{4}{*}{ Gold et al (2006) } & 64 & 26 & Any work at all \\
\hline & & & Hours worked \\
\hline & & & Job tenure \\
\hline & & & Income \\
\hline \multirow[t]{4}{*}{ Latimer et al (2006) } & 47 & 18 & Hours worked \\
\hline & & & Wages \\
\hline & & & Job tenure (weeks in longest job) \\
\hline & & & Non-vocational outcomes (quality of life, social \\
\hline
\end{tabular}

IPS, individual placement scheme.

I. $18.2 \%$ for psychosocial rehabilitation and $27.5 \%$ for standard care.

(Bebbington et al, 2005) found that $32.8 \%$ of the British sample had experienced homelessness in their lifetime compared with $8.4 \%$ in Germany and $12.9 \%$ in France. The rate in London was even higher $(43 \%)$ and $13.2 \%$ of the British sample had experienced rooflessness, despite those who were currently roofless being excluded from the study.

Large US schizophrenia studies consistently find homelessness to be associated with substance misuse and severity of symptoms, but have also found associations with African-American ethnicity (Folsom et al, 2005), lower global functioning (Olfson et al, 1999) and more autistic preoccupations (Opler et al, 2001).

Housing instability in people with schizophrenia predisposes to institutionalisation in prisons and hospitals (Appleby \& Desai, 1987), non-adherence with treatment, psychosocial problems (Drake et al, 1989) and decreased quality of life (Lehman $e t$ $a l, 1995)$. Physical and sexual abuse are extremely common in both male and female homeless (Wenzel et al, 2000). Mortality is more than 3 times higher in the homeless (Hibbs et al, 1994). Outcomes may be poorer for homeless people with schizophrenia in urban compared with rural areas (Drake et al, 1991).

\section{Risk to society}

The proportions of homeless people with schizophrenia vary with levels of social and mental health provision, for example $12 \%$ for males in Munich (Fichter et al, $1999)$ and $23 \%$ for males in Sydney (Teesson et al, 2004), but are higher in urban areas and significantly higher in the female homeless $(46 \%$ in Sydney; Teesson et al, 2004).

\section{Measurement}

'Rooflessness' refers to those living on the streets, and defines the group of most public concern but which is hardest to locate or follow-up. Most studies (e.g. Folsom et al, 2005) use a looser definition of having no fixed address and include people living in hostels and emergency accommodation. Some researchers have further widened the concept to include a spectrum of 'housing instability', signifying tenuousness of housing tenure and associated stress (Drake et al, 1991). This group of so-called sofa-surfers move frequently between friends, family and emergency housing.

There are no valid national databases of housing because of unofficial rental, unregistered housing by friends and family, and the rapid movements of individuals. Case manager rating scales of housing instability have been used, such as a 5-point Likert scale sceening device (Drake et al, 1991), which rates accommodation from 'highly supportive' to 'highly stressful'. This may help to identify people with housing problems who can then be given a more detailed structured interview

However, people who are living on the streets, especially those with prominent negative symptoms or an itinerant lifestyle, are less likely to be in regular contact with mental health services, thus rates of homelessness in people with schizophrenia may be underestimated. Assertive screening of the homeless for mental illness might reduce the exclusion of this group from mental health services.

\section{UNEMPLOYMENT}

\section{Prevalence and risk factors}

The European Schizophrenia Cohort (Bebbington et al, 2005) found that only $11.5 \%$ of the British sample were actively employed, including sheltered employment. The French rate was similar $(12.9 \%)$ but the German much higher (30.3\%). Estimates of about $22 \%$ have been made in both the USA (Mechanic et al, 2002) and Australia (Carr et al, 2004). More encouragingly, the International Study of Schizophrenia (IsoS) found that $37 \%$ of people with schizophrenia had received paid work for most of the past 2 years (Harrison et al, 2001), but attrition rates were high.

The gradual decline in rates of employment over many years leading up to diagnosis in a large Danish population cohort (Agerbo et al, 2004) suggests impairment during the prodromal phase. Rates of employment deteriorate further after first presentation (Mechanic et al, 2002; Agerbo et al, 2004). Among people with schizophrenia, past admission to hospital predicts 
current unemployment (Munk-Jorgensen \& Mortensen, 1992).

Unemployment is associated with decreased quality of life in schizophrenia (Caron et al, 2005). Lewine (2005) showed that job expectation prior to the onset of schizophrenia significantly correlated with depression and hopelessness, and both were increased in higher socio-economic groups.

Educational attainment is the best protective factor for employment in people with schizophrenia, as in the general population (Mechanic et al, 2002). Cognitive functioning is a significant predictor of job tenure (Gold et al, 2002) and response to vocational rehabilitation (McGurk \& Mueser, 2004).

\section{Risk to society}

The cost of unemployment owing to schizophrenia is considerable. Numbers of American recipients of disability benefits for schizophrenia rose by $35 \%$ between 1994 and 2003 (Rosenheck, 2006). Not surprisingly several initiatives are underway to improve employment in this group. A Cochrane review (Crowther et al, 2001) concluded that supported employment, such as individual placement and support (Bond et al, 1997), is more effective than pre-vocational training for obtaining competitive employment.

\section{Measurement}

Employment is not an all-or-nothing phenomenon and should be considered in terms of quantity and quality, both for the individual and research purposes. Studies examining the impact of individual placement schemes in assisting attaining employment have used quite consistent measures of employment (Table 2). These studies all principally examined the proportion of people with mental health problems who attained competitive employment, which has been defined as a job in which payment is at least the minimum wage, is not reserved for people with disabilities and fewer than half of the person's co-workers have disabilities (Latimer et al, 2006). However, sheltered employment, although less lucrative and unable to supply the same level of integration, can also increase skills and self-esteem.

Quantity of employment can be measured by either hours worked or income earned. Quality of employment can be measured by: (a) job tenure, i.e how long each job is held; working for short periods in a variety of jobs is likely to be less fullfilling and give a lower sense of financial security; (b) job satisfaction; and (c) secondary benefits, such as social contact, quality of life, etc.

The studies described above all used a combination of self-report and keyworker ratings every 6 months. Latimer et al (2006) supplemented these interviews with two monthly telephone interviews. However, self-report measures may overestimate levels of employment owing to bias arising from social desirability, denial and grandiosity. Few studies have included employer interviews, which participants may not consent to.

Receiving benefits has been used as a proxy measure for employment. However, some unemployed people are supported by savings or family members/partners and are either ineligible or choose not to collect benefits. Another group collect benefits but work legally part-time, or work occasionally or frequently 'off the books'.

\section{CONCLUSIONS}

Schizophrenia is strongly associated with a range of adverse outcomes, which have an impact at the societal level. There is much intercorrelation between these outcomes, suggesting the possibility of a domino-like effect for an individual person, whereby each outcome leads to another. To limit this downward spiral, it is crucial that all of these outcomes are considered simultaneously. Reducing these outcomes would require implementation of a combination of strategies at national, local and patient levels (e.g. the matrix model of healthcare provision; Tansella \& Thornicroft, 1998).

There are few standardised definitions, let alone validated measures for these outcomes, which makes comparison or collation of research findings problematic. A systematic review of studies proposing implementation of routine mental health outcome measures (Slade, 2002) identified few studies examining any of the outcomes discussed here. For clinical purposes, therefore, the mere consideration of these outcomes, alongside thorough assessment and the use of multiple information sources, allows the best chance of a positive outcome. For research purposes, a collection of validated and brief assessments or even a single instrument to systematically measure these societal outcomes would be extremely useful.

\section{REFERENCES}

Addington, J. \& Duchak, V. (1997) Reasons for substance use in schizophrenia. Acta Psychiatrica Scandinavica, 96, 329-333.

Agerbo, E., Bryne, M., Eaton, W. W., et al (2004)

Marital and labor market status in the long run in schizophrenia. Archives of General Psychiatry, 6I, 28-33.

Ananth, I., Vandewater, S., Kamal, M., et al (1989)

Missed diagnosis of substance abuse in psychiatric patients. Hospital and Community Psychiatry, 40,

297-299.

Appleby, L. \& Desai, P. (1987) Residential instability: perspective on system imbalance. American journal of Orthopsychiatry, 57, 515-524.

Appleby, L., Cooper, J., Amos, T., et al (1999a)

Psychological autopsy study of suicides by people aged under 35. British journal of Psychiatry, 175, 168-174.

Appleby, L., Shaw, J., Amos, T., et al (1999b) Suicide within 12 months of contact with mental health services: national clinical survey. BMJ, 318, 1235-1239.

Arseneault, L., Moffitt, T. E., Caspi, A., et al (2000)

Mental disorders and violence in a total birth cohort: results from the Dunedin study. Archives of General Psychiatry, 57, 979-986.

Arseneault, L., Cannon, M., Witton, J., et al (2004)

Causal association between cannabis and psychosis: examination of the evidence. British Journal of Psychiatry, 184, $110-117$.

Bebbington, P. E., Angermeyer, M., Azorin, J., et al (2005) The European Schizophrenia Cohort: a naturalistic prognostic and economic study Social Psychiatry and Psychiatric Epidemiology, 40, 707-717.

Berman, A. H., Bergman, H., Palmstierna, T., et al

(2005) Evaluation of the Drug Use Disorders

Identification Test (DUDIT) in criminal justice and detoxification settings and in a Swedish population sample. European Addiction Research, II, 22-31.

Blanchard, J. J. \& Brown, S. A. (1998) Structured diagnoistic interview schedules. In Comprehensive Clinical Psychology (Vol. 3) (ed. C. R. Reynolds), pp. 97-130. Elsevier.

Bond, G. R., Drake, R. E., Mueser, K.T., et al (1997) An update on supported employment for people with severe mental illness. Psychiatric Services, 48, 335-346.

Bonta, J., Law, M. \& Hanson, K. (1998) The prediction of criminal and violent recidivism among mentally disordered offenders: a meta-analysis. Psychological Bulletin, 123, 123-142.

Boutros, M., Bowers, M. \& Quilan, D. (1998)

Chronological association between increases in drug abuse and psychosis in Conneticut State Hospitals. Journal of Neuropsychiatry and Clinical Neuroscience, 10 48-54

Breier, A., Schreiber, J. L., Dyer, J., et al (1991) National Institute of Mental Health longitudinal study of chronic schizophrenia. Prognosis and predictors of outcome. Archives of General Psychiatry, 48, 239-246.

Brekke, J. S., Prindle, C., Bae, S.W., et al (200I) Risks for individuals with schizophrenia who are living in the community. Psychiatric Services, 52, 1358-1366.

Brennan, P. A., Mednick, S. A. \& Hodgins, S. (2000) Major mental disorders and criminal violence in a Danish birth cohort. Archives of General Psychiatry, 57, 494-500.

Brown, S., Barraclough, B. \& Inskip, H. (2000)

Causes of the excess mortality of schizophrenia. British journal of Psychiatry, 177, 212-217.

Buchanan, A. \& Leese, M. (200I) Detention of people with dangerous severe personality disorders: a systematic review. Lancet, 358, 1955-1959 
Caldwell, C. B. \& Gottesman, I. I. (1990)

Schizophrenics kill themselves too: a review of risk factors for suicide. Schizophrenia Bulletin, 16, 57I-589.

Caldwell, C. B. \& Gottesman, I. I. (1992)

Schizophrenia - a high-risk factor for suicide: clues to risk reduction. Suicide and Life Threatening Behaviour, 22 479-493.

Cantor-Graae, E., Nordstrom, L. G. \& McNeil, T. F. (200I) Substance abuse in schizophrenia: a review of the literature and a study of correlates in Sweden.

Schizophrenia Research, 48, 69-82.

Carey, K. B., Maisto, S. A., Carey, M. P., et al (200I) Measuring readiness to change substance misuse among psychiatric outpatients: reliability and validity of self report measures. Journal of Studies on Alcohol, 62, 79-88.

Caron, J., Mercier, C., Diaz, P., et al (2005) Sociodemographic and clinical predictors of quality of life in patients with schizophrenia or schizo-affective disorder. Psychiatric Research, I37, 203-213.

\section{Carr, V. J., Lewin, T. J., Neil, A. L., et al (2004)} Premorbid, psychosocial and clinical predictors of the costs of schizophrenia and other psychoses. British Journal of Psychiatry, 184, 517-525.

Cascardi, M., Mueser, K.T., De Giralomo, J., et al (1996) Physical aggression against psychiatric inpatients by family members and partners. Psychiatric Services, $\mathbf{4 7}$ $531-533$

Copas, J. \& Marshall, P. (1998) The offender group reconviction scale: a statistical reconviction score for use by probation officers. Applied Statistics, 47, 159-17|.

Crowther, R. E., Marshall, M., Bond, G.R, et al (200I) Helping people with severe mental illness to obtain work: systematic review. BMJ, 322, 204-208.

Dixon, L., Haas, G., Wieden, P., et al (1990) Acute effects of drug abuse in schizophrenic patients' self reports. Schizophrenia Bulletin, 16, 69-79.

Dolan, M. \& Doyle, M. (2000) Violence risk prediction Clinical and actuarial measures and the role of the Psychopathy Checklist. British Journal of Psychiatry, I77, 303-311.

Douglas, K., Webster, C., Hart, S., et al (200I) HCR20 Violence Risk Management Companion Guide. Mental Health, Law and Policy Insititute, Simon Fraser University. Department of Mental Health Law and Policy, Unitversity of South Florida.

Drake, R. E., Wallach, M. A. \& Hoffman, J. S. (1989) Housing instability and homelessness among aftercare patients of an urban state hospital. Hospital and Community Psychiatry, 40, 46-5।.

Drake, R. E., Osher, F. C, Noordsy, D. L., et al (1990) Diagnosis of alcohol use disorders in schizophrenia. Schizophrenia Bulletin, 16, 57-67.

Drake, R. E., Wallach, M. A., Teague, G. B., et al (199I) Housing instability and homelessness among rural schizophrenic patients. American Journal of Psychiatry, 148, 330-336.

Drake, R. E., McHugo, G. J., Becker, D. R., et al (1996) The New Hampshire study of supported employment for people with severe mental illness. Journal of Consulting and Clinical Psycholology, 64, 391-399.

Drake, R. E., McHugo, G. J., Bebout, R. R., et al (1999) A randomized clinical trial of supported employment for inner-city patients with severe mental disorders. Archives of General Psychiatry, 56, 627-633.

Duke, P. J., Pantelis, C. \& Barnes, T. R. (1994) South Westminster schizophrenia survey. Alcohol use and its relationship to symptoms, tardive dyskinesia and illness onset. British Journal of Psychiatry, 164, 630-636.

Duke, P. J., Pantellis C., McPhillips, M. A., et al (200I) Comorbid non-alcohol substance misuse among people with schizophrenia. Epidemiological study in central London. British Journal of Psychiatry, 179, 509-

Elbogen, E. B., Van Dorn, R. A., Swanson, J.W. et al (2006) Treatment engagement and violence risk in mental disorders. British Journal of Psychiatry, $\mathbf{1 8 9}$ 354-360.

Elliot, D. A., Huizinga, D. \& Morse, B. J. (1986) Selfreported violent offending: a descriptive analysis of juvenile violent offenders and their offending careers Journal of Interpersonal Violence, I, 472-513.

Eronen, M., Hakola, P. \& Tiihonen, J. (1996) Menta disorders and homicidal behaviour in Finland. Archives of General Psychiatry, 53, 497-50I.

Fazel, S. \& Grann, M. (2006) The population impact of severe mental illness on violent crime. American Journal of Psychiatry 163, 1397-1403.

Fergusson, D. M., Horwood, L. J., Lynskey, M.T., et al (2003) Early reactions to cannabis predict later dependence. Archives of General Psychiatry, 60, 10331039

Fichter, M., Quadflieg, N., Koniarczyk, M., et al (1999) Mental illness in homeless men and women in Munich. Psychiatrische Praxis, 26, 76-84.

Folsom, S. P., Hawthorne, W., Lindamer, L., et al (2005) Prevalence and risk factors for homelessness and utilization of mental health services among 10,340 patients with serious mental illness in a large public mental health system. American Journal of Psychiatry, 162 370-376.

Gold, J. M., Godberg, R.W., McNary, S. W., et al (2002) Cognitive correlates of job tenure among patients with severe mental illness. American Journal of Psychiatry, 159, 1395-1402.

Gold, P. B., Meisler, N., Santos, A. B., et al (2006) Randomized trial of supported employment integrated with assertive community treatment for rural adults with severe mental illness. Schizophrenia Bulletin, 32. 378-395.

Gossop, M., Darke S., Griffiths, P., et al (1995) The Severity of Dependence Scale (SDS): psychometric properties of the SDS in English and Australian samples of heroin, cocaine and amphetamine users. Addiction, 90, 607-614

Gray, N. S., Snowden, R. J., MacCulloch, S., et al (2004) Relative efficacy of criminological, clinical, and personality measures of future risk of offending in mentally disordered offenders: a comparative study of HCR-20, PCL:SV, and OGRS. Journal of Consulting and Clinical Psychology, 72, 523-530.

Haddock, G., Barrowclough, C., Tarrier, N., et a (2003) Cognitive-behavioural therapy and motivationa intervention for schizophrenia and substance misuse: 18 month outcomes of a randomised controlled trial. British Journal of Psychiatry, 183, 418-426.

Hambrecht, M. \& Hafner, H. (1996) Substance abuse and the onset of schizophrenia. Biological Psychiatry, 40, II55-1163.

Harrison, G., Hopper, K., Craig, T., et al (2001) Recovery from psychotic illness: a I5- and 25-year international follow-up study. British Journal of Psychiatry, 178, 506-517.

Hart, S. D., Cox, D. N. \& Hare, R. D. (1995) The Hare Psychopathy Checklist - Screening Version (PCL:SV). MultiHealth Systems.

Haw, C., Hawton, K., Sutton, L., et al (2005) Schizophrenia and deliberate self-harm: a systematic review of risk factors. Suicide and Life Threatening Behaviour, 35, 50-62.

Hawton, K., Rodham, K., Evans, E., et al (2002) Deliberate self harm in adolescents: self report survey in schools in England. BMJ, 325, 1207-1211.
Hawton, K., Sutton, L., Haw, C., et al (2005) Schizophrenia and suicide: systematic review of risk factors. British Journal of Psychiatry, 187, 9-20.

Healy, D., Harris, M., Tranter, R., et al (2006) Lifetime suicide rates in treated schizophrenia: 1875-1924 and 1994-1998 cohorts compared. British Journal of Psychiatry, 188, 223-228.

Hibbs, J. R., Benner, L., Klugman, L., et al (1994) Mortality in a cohort of homeless adults in Philadelphia. New England Journal of Medicine, 33I, 304-309.

Hiday, V. A., Swartz, M. S., Swanson, J.W., et al (2002) Impact of outpatient commitment on victimization of people with severe mental illness. American Journal of Psychiatry, 159, 1403-14II.

Hodgins, S. (1992) Mental disorder, intellectua deficiency and crime: evidence from a birth cohort. Archives of General Psychiatry, 49, 476-483.

Hoff, R. A. \& Rosenheck, R. A. (1999) The cost of treating substance abuse patients with and without comorbid psychiatric disorders. Psychiatric Services, 50 1309-1315.

Hunt, G. E., Bergen, J. \& Bahir, M. (2002) Medication compliance and comorbid substance misuse in schizophrenia: impact on community survival 4 years after relapse. Schizophrenia Research, 54, 253-264.

Jablensky, A., Sartorius, N., Ernberg, G., et al (1992) Schizophrenia: manifestations, incidence and course in different cultures. A World Health Organisation tencountry study. Psychological Medicine Monograph Supplement, 20, I-97.

Janowsky, D. S., El-Yousef, M. K., Davis, J. M., et al (1973) Provocation of schizophrenic symptoms by intravenous administration of methylphenidate. Archives of General Psychiatry, 28, 185-191.

Kirkpatrick, B., Amador, X., Flaum, M., et al (1996) The deficit syndrome in the DSM-IV field trial: alcohol and other drug abuse. Schizophrenia Research, 20, 69-77. Kroner, D. G. (2005) Issues in violent risk assessment: lessons learned and future directions. Journal of Interpersonal Violence, 20, 23I-235.

Lam, J. A. \& Rosenheck, R. (1998) The effect of victimization on clinical outcomes of homeless persons with serious mental illness. Psychiatric Services, 49, 678-683.

Lamb, H. R. (1982) Young adult chronic patients: the new drifters. Hospital and Community Psychiatry, 33. 465-468.

Latimer, E. A., Lecomte, T., Becker, D. R., et a (2006) Generalisability of the individual placement and support model of supported employment: results of a Canadian randomised controlled trial. British Journal of Psychiatry, 189, 65-73.

Lehman, A. F., Kernan, E., DeForge, B. R., et al (1995) Effects of homelessness on the quality of life of persons with severe mental illness. Psychiatric Services, 46, 922-926.

Lehman, A. F., Goldberg, R., Dixon, L. B., et al (2002) Improving employment outcomes for persons with severe mental illnesses. Archives of General Psychiatry. 59, 165-172.

Lewine, R. R. (2005) Social class of origin, lost potential, and hopelessness in schizophrenia. Schizophrenia Research, 76, 329-335.

Ley, A., Jeffrey, D. P., McClaren, S., et al (2000) Treatment programmes for people with both severe mental illness and substance misuse. Cochrane Database of Systematic Reviews, issue 2. Update software.

Liberman, R. P., Mueser, K. T., Wallace, C. J., et a (1986) Training skills in the psychiatrically disabled: learning coping and competence. Schizophrenia Bulletin 12, 631-647. 
Marsden, J., Gossop, M., Stewart, D., et al (1998) The Maudsley Addiction Profile (MAP): a brief instrument for assessing treatment outcome. Addiction, 93, 18571867.

McCreadie, R. G. (2002) Use of drugs, alcohol and tobacco by people with scizophrenia: case-contro study. British Journal of Psychiatry, 18I, 32I-325.

McGurk, S. R. \& Mueser, K.T. (2004) Cognitive

functioning, symptoms and work in supported environment: a review and heuristic model. Schizophrenia Research, 70, 147-174.

Mechanic, D., Blider, S. \& McAlpine, D. D. (2002) Employing persons with serious mental illness. Health Affairs (Millwood), 21, 242-253.

Miles, C. P. (1977) Conditions predisposing to suicide: a review. Journal of Nervous and Mental Disease, 164 23I-246.

Mills, J. F. (2005) Advances in the assessment and prediction of interpersonal violence. Journal of Interpersonal Violence, 20, 236-24I.

Moran, P. \& Hodgins, S. (2004) The correlates of comorbid antisocial personality disorder in schizophrenia. Schizophrenia Bulletin, 30, 791-802.

Mueser, K. T. \& Drake, R. E. (1998) Dual diagnosis: review of etiological theories. Addictive Behaviors, 23. 717-734.

Mueser, K. T., Clark, R. E., Haines, M., et al (2004) The Hartford study of supported employment for persons with severe mental illness. Journal of Consulting and Clinical Psychology, 72, 479-490.

Munk-Jorgensen, P. \& Mortensen, P. B. (1992) Social outcome in schizophrenia: a 13-year follow-up. Social Psychiatry and Psychiatric Epidemiology, 27, 129-134.

Nordentoft, M., Jeppesen, P., Abel, M., et al (2002) OPUS study: suicidal behaviour, suicidal ideation and hopelessness among patients with first-episode psychosis. One-year follow-up of a randomised controlled trial. British Journal of Psychiatry, 18I (suppl. 43), s98-106.

Olfson, M., Mechanic, D., Hansell, S., et al (1999) Prediction of homelessness within three months of discharge among inpatients with schizophrenia. Psychiatric Services, 50, 667-673.

Oliver, J. (1991) The social care directive: development of a quality of life profile for use in community services for the mentally ill. Social Work and Social Sciences Review, 3, 53-60.

Opler, L. A., White, L., Caton, C. L., et al (200I) Gender differences in the relationship of homelessness to symptom severity, substance abuse, and neuroleptic noncompliance in schizophrenia. Journal of Nervous and Mental Disease, 189, 449-456.

Palmer, B. A., Pankratz, V. S. \& Bostwick, J. M. (2005) The lifetime risk of suicide in schizophrenia: a reexamination. Archives of General Psychiatry, 62 , 247-253.

Platt, S., Bille-Brahe, U., Kerkhof, A., et al (1992) Parasuicide in Europe: the WHO/EURO multicentre study on parasuicide. I. Introduction and preliminary analysis for 1989. Acta Psychiatrica Scandinavica, 85 , 97-104.

Powell, J., Geddes, J., Howton, K., et al (2000) Suicide in psychiatric hospital in-patients. Risk factors and their predictive power. British Journal of Psychiatry, 176, 266272

Pristach, C. A. \& Smith, C. M. (1996) Self reported effects of alcohol use on symptoms of schizophrenia, Psychiatric Services 47, 421-423.

Reiger, D. A., Farmer, M. E., Rae, D. S., et al (1990) Comorbidity of mental disorders with alcohol and other

IAIN KOOYMAN, MRCPsych, KIMBERLIE DEAN, MRCPsych, Department of Forensic Mental Health Science, SAMUEL HARVEY MRCPsych, ELIZABETH WALSH, MD, Department of Psychological Medicine, Institute of Psychiatry, London, UK

Correspondence: Dr lain Kooyman, Department of Forensic Mental Health Science, Institute of Psychiatry, De Crespigny Park, London SE5 8AF, UK. Email: lain.Kooyman@iop.kcl.ac.uk

drug abuse: results from the Epidemiological Catchment Area (ECA) study. JAMA, 264, 25II-25I8.

Rosenheck, R. A. (2006) Outcomes, costs and policy caution: a commentary on the cost utility of the latest antipsychotic drugs in schizophrenia study. Archives of General Psychiatry, 63, 1074-1076.

Sainsbury, P. \& Jenkins, J. S. (1982) The accuracy of officially reported suicide statistics for purposes of epidemiological research. Journal of Epidemiological Community Health, 36, 43-48.

Sainsbury Centre for Mental Health (1998) Keys to Engagement: Re-View of Care for People with Severe Mental IIIness who are Hard to Engage with Services. Sainsbury Centre for Mental Health.

Saunders, J. B., Aasland, O. G., Babor, T. F., et a (1993) Developement of the Alcohol Use Disorders Identification Test (AUDIT): WHO Collaborative Project on Early Detection of Persons with Harmful Alcohol Consumption - II. Addiction, 88, 791-804.

Scott, H., Johnson, S., Menezes, P., et al (1998) Substance misuse and risk of aggression and offending among the severely mentally ill. British journal of Psychiatry, 172, 345 -350.

Seibyl, J., Satel, S., Anthony, D., et al (1993) Effects of cocaine on hospital course in schizophrenia. Journal of Nervous and Mental Disease, I8I, 3I-37.

Serper, M. R., Alpert, M. \& Trujillo, J. (1996) Recent cocaine use decreases negative signs in acute schizophrenia: a case study over two consecutive admissions. Biological Psychiatry, 39, 816-818.

Sevy, S., Robinson, D. G., Holloway S., et al (2001) Correlates of substance misuse in patients with firstepisode schizophrenia and schizoaffective disorder. Acto Psychiatrica Scandinavica, 104, 367-374.

Silver, E. (2002) Mental disorder and violent victimization: the mediating role of involvement in conflicted social relationships. Criminology, 40, 191-211.

Silver, E., Arseneault, L., Langley, J., et al (2005) Mental disorder and violent victimization in a total birth cohort. American Journal of Public Health, 95, 2015-2021. Skegg, K. (2005) Self-harm. Lancet, 366, 147I-1483.

Slade, M. (2002) What outcomes to measure in routine mental health services, and how to assess them: a systematic review. Australian and New Zealand journal of Psychiatry, 36, 743-753.

Soyka, M., Albus, M., Kathmann, N., et al (1993) Prevalence of alcohol and drug abuse in schizophrenic inpatients. European Archives in Psychiatry and Clinical Neuroscience, 242, 362-372.

Speechley, M. \& Stavraky, K. M. (1991) The adequacy of suicide statistics for use in epidemiology and public health. Canadian Journal of Public Health, 82, 38-42.

Spitzer, R. L., Williams, J. B., Gibbon, M., et al (1994) Structured Clinical Interview for DSM-IV Axis I Disorder Patient Edition. New York State Psychiatric Institute.

Steadman, H. J., Mulvey, E. P., Monahan, J., et al (1998) Violence by people discharged from acute psychiatric inpatient facilities and by others in the same neighborhoods. Archives of General Psychiatry, 55, I-9.
Swanson, J., Estroff, S., Swartz M., et al (1997) Violence and severe mental disorder in clinical and community populations: the effects of psychotic symptoms, comorbidity, and lack of treatment. Psychiatry, 60, 1-22.

Swanson J., Van Dorn R., Monahan J., et al (2006) Violence and leveraged community treatment for persons with mental disorders. American Journal of Psychiatry, 163, 1404-1411.

Swartz, M. S., Swanson, J.W. \& Hannon, M. J. (2003) Detection of illicit substance use in persons with schizophrenia. Psychiatric Services, 54, 89I-895.

Swartz, M. S., Wagner, R., Swanson, J.W., et al (2006) Substance use in persons with schizophrenia. Baseline prevalence and correlates from the NIMH CATIE Study Journal of Nervous and Mental Disease, 194, 164-172.

Swofford, C. D., Kasckow, J.W., Scheller-Gilkey, G., et al (1996) Substance use: a powerful predictor of relapse in schizophrenia. Schizophrenia Research, 20, 145-151.

Tansella, M. \& Thornicroft, G. (1998) A conceptua framework for mental health services: the matrix model. Psychological Medicine, 28, 503-508.

Taylor, P. J. (1998) When symptoms of psychosis drive serious violence. Social Psychiatry and Psychiatric Epidemiology, 33, S47-S54.

Teeson, M., Hodder, T. \& Buhrich, N. (2004)

Psychiatric disorders in homeless men and women in inner Sydney. Australian and New Zealand Journal of Psychiatry, 38, 162-168.

Teplin, L. A. (1990) The prevalence of severe mental disorder among urban jail detainees: comparison with the epidemiologic catchment area program. American Journal of Public Health, 80, 663-669.

Teplin, L. A., McClelland, G. M., Abram, K. H., et a (2005) Crime victimization in adults with severe mental illness: comparison with the National Crime

Victimization Survey. Archives of General Psychiatry, 62 9|1-92|

Tiihonen, J., Isohanni, M., Räsänen, P., et al (1997) Specific major mental disorders and criminality: a 26-year prospective study of the 1966 northern Finland birth cohort. American Journal of Psychiatry, 154, 840-845.

Wallace, C., Mullen, P. E. \& Burgess, P. (2004)

Criminal offending in schizophrenia over a 25 -year period marked by deinstitutionalization and increasing prevalence of comorbid substance use disorders. American Journal of Psychiatry, 161, 716-727.

Ward, J. C. \& Dow, M. G. (1995) Functional Assessment Rating Scale. Department of Community Mental Health, University of South Florida.

Wenzel, S. L., Koegel, P. \& Gelberg, L. (2000)

Antecedents of physical and sexual victimization among homeless women: a comparison to homeless men. American Journal of Community Psychology, 28, 367-390.

World Health Organization (1992) The Life Chart. WHO

Wong, S. \& Gordon, A. (2000) Violence Risk Scale. Regional Psychiatric Centre, Saskatoon. 